\title{
Endoscopic management of biliary complications following liver transplantation after donation from cardiac death donors
}

\author{
Kris P Croome MD MS ${ }^{1,2}$, Vivian McAlister MD ${ }^{1,2}$, Paul Adams MD PhD ${ }^{3}$, Paul Marotta MD ${ }^{1,3}$, \\ William Wall $\mathrm{MD}^{1,2}$, Roberto Hernandez-Alejandro $\mathrm{MD}^{1,2}$
}

KP Croome, V McAlister, P Adams, P Marotta, W Wall, R Hernandez-Alejandro. Endoscopic management of biliary complications following liver transplantation after donation from cardiac death donors. Can J Gastroenterol 2012;26(9):607-610.

BACKGROUND: Previous studies have shown a higher incidence of biliary complications following donation after cardiac death (DCD) liver transplantation compared with donation after brain death (DBD) liver transplantation. The endoscopic management of ischemic type biliary strictures in patients who have undergone DCD liver transplants needs to be characterized further.

METHODS: A retrospective institutional review of all patients who underwent DCD liver transplant from January 2006 to September 2011 was performed. These patients were compared with all patients who underwent DBD liver transplantation in the same time period. A descriptive analysis of all DCD patients who developed biliary complications and their subsequent endoscopic management was also performed.

RESULTS: Of the 36 patients who received DCD liver transplants, $25 \%$ developed biliary complications compared with $13 \%$ of patients who received DBD liver transplants $(\mathrm{P}=0.062)$. All DCD allograft recipients who developed biliary complications became symptomatic within three months of transplantation. Ischemic type biliary strictures in DCD allograft recipients included disseminated biliary strictures in two patients, biliary strictures of the hepatic duct bifurcation in three patients and biliary strictures of the donor common hepatic duct in three patients.

CONCLUSIONS: There was a trend toward increasing incidence of total biliary complications in recipients of DCD liver allografts compared with those receiving DBD livers, and the rate of diffuse ischemic cholangiopathy was significantly higher. Focal ischemic type biliary strictures can be treated effectively in DCD liver transplant recipients with favourable results. Diffuse ischemic type biliary strictures in DCD liver transplant recipients ultimately requires retransplantation.

Key Words: Donation after cardiac death; ERCP; Ischemic cholangiopathy; Ischemic type biliary strictures; Stenting; Warm ischemia time

$\mathbf{R}$ enewed interest in donation after cardiac death (DCD) has Remerged as more transplant programs pursue extended criteria donors to increase the pool of donor livers. Studies have shown a higher incidence of biliary complications after DCD liver transplant (LT) compared with donation after brain death (DBD) LT (1-5). The reported incidence of biliary complications after liver transplantation using allografts from DCD ranges from $32 \%$ to $60 \%$, compared with $5.8 \%$ to $15 \%$ in DBD allografts (1-6).

The biliary tract is supplied with arterial blood by the peribiliary vascular plexus. During DCD liver procurement, warm ischemia time (WIT) is defined as the time elapsed from withdrawal of life support

\section{La prise en charge endoscopique des complications biliaires après une transplantation hépatique suivant un don d'organe après une mort cardiaque}

HISTORIQUE : Des études passées ont démontré une plus forte incidence de complications biliaires après une transplantation hépatique suivant un don d'organe après une mort cardiaque (DMCa) qu'après une mort cérébrale (DMCé). La prise en charge endoscopique de constrictions biliaires de type ischémique doit être caractérisée davantage chez les patients qui ont subi une transplantation hépatique suivant un DMCa.

MÉTHODOLOGIE : Les auteurs ont procédé à une analyse rétrospective institutionnelle de tous les patients qui ont subi une transplantation hépatique suivant un DMCa entre janvier 2006 et septembre 2011. Ils ont comparé ces patients à tous ceux qui ont subi une transplantation hépatique suivant un DMCé pendant la même période. Ils ont également effectué une analyse descriptive de tous les patients qui ont développé des complications biliaires après un DMCa et de leur prise en charge endoscopique subséquente.

RÉSULTATS : Chez les 36 patients qui ont subi une transplantation hépatique suivant un DMCa, $25 \%$ ont développé des complications biliaires par rapport à $13 \%$ de ceux qui ont subi une transplantation hépatique après un DMCé $(\mathrm{P}=0,062)$. Tous les receveurs d'une allogreffe qui ont développé des complications biliaires après un DMCa sont devenus symptomatiques dans les trois mois suivant la transplantation. Les constrictions biliaires de type ischémique chez les receveurs d'une allogreffe suivant un DMCa incluaient des constrictions biliaires disséminées chez deux patients, des constrictions biliaires de la bifurcation du canal hépatique chez trois patients et des constrictions biliaires du canal hépatique commun du donneur chez trois patients.

CONCLUSIONS : On constatait une tendance vers l'augmentation de l'incidence de complications biliaires totales chez des receveurs d'une allogreffe hépatique suivant un DMCa par rapport aux receveurs d'un foie suivant un DMCé, et le taux de cholangiopathies ischémiques diffuses était considérablement plus élevé. Les constrictions biliaires focales de type ischémique peuvent donner des résultats favorables chez les receveurs d'une transplantation hépatique suivant un DMCa. Les constrictions biliaires diffuses de type ischémique chez les receveurs d'une transplantation hépatique suivant un DMCa finissent par avoir besoin d'une nouvelle transplantation.

until aortic cold perfusion is initiated. The lack of arterial perfusion of the biliary tree during this WIT results in injury to the biliary epithelium due to its sensitivity to ischemic injury $(7,8)$. Lack of arterial perfusion to the peribiliary vascular plexus may contribute to the ischemic necrosis of the biliary system mucosa and cause biliary strictures (9). Diffuse ischemic cholangiopathy is a serious complication that can lead to early graft failure (4). Retransplant is generally regarded as the only treatment for ischemic cholangiopathy.

Historically, first-line treatments for biliary complications, including strictures, were surgery or percutaneous transhepatic cholangiography with balloon dilation $(10,11)$. Endoscopic management is

${ }^{1}$ Multi-Organ Transplant Program, London Health Sciences Centre; ${ }^{2}$ Department of Surgery, Division of General Surgery; ${ }^{3}$ Division of Gastroenterology,

The University of Western Ontario, London, Ontario

Correspondence: Dr Roberto Hernandez-Alejandro, Multi-Organ Transplant Program, London Health Sciences Centre, The University of Western

Ontario, London, Ontario N6A 5A5. Telephone 519-663-2920, fax 519-663-3858, e-mail roberto.hernandezalejandro@lhsc.on.ca

Received for publication November 25, 2011. Accepted January 14, 2012 


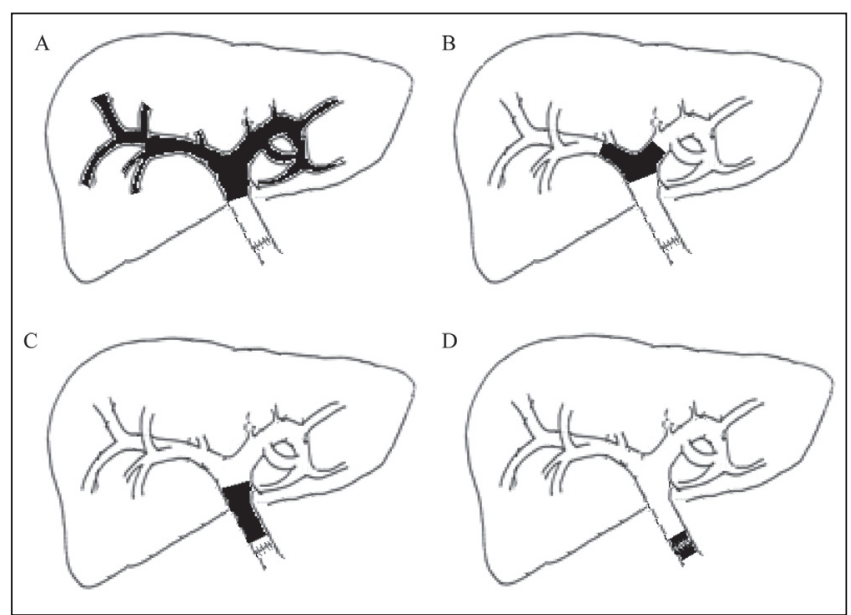

Figure 1) Classification of biliary strictures. A Disseminated. B Localized hepatic duct bifurcation. C Localized donor common hepatic duct. D Localized anastomotic

currently an effective treatment for biliary complications after liver transplantation $(1,12)$. The present study aimed to further characterize the endoscopic management of ischemic type biliary strictures (ITBS) in patients who have undergone DCD LT.

\section{METHODS}

After approval from the Institutional Review Board, a retrospective review was performed on all patients who underwent DCD LT between January 2006 and September 2011. These were compared with all patients who underwent DBD LT in the same time period. Data on these patients were prospectively entered into the transplant database.

All organs were procured from controlled DCD donors using techniques previously published (13). Withdrawal was performed in the intensive care unit in $33(92 \%)$ patients and in the operating room in three $(8 \%)$ patients. The bile duct was anastomosed in a duct-to-duct fashion with a continuous absorbable suture. WIT was defined as the time elapsed from withdrawal of life support until aortic cold perfusion was initiated. Mean arterial pressure (MAP) was recorded in all patients from the time of withdrawal of life support until declaration of death. Presently, a maximal WIT of $30 \mathrm{~min}$ is used and, when deciding to use livers, a maximal donor age of 55 years is used as a cutoff; however, each case is assessed individually. During the initial development of the DCD program, several organs with longer WITs were used. Rewarming ischemia time during anastomosis in the recipient ranged from $45 \mathrm{~min}$ to $70 \mathrm{~min}$.

Endoscopic retrograde cholangiopancreatography (ERCP) was performed postoperatively when indicated based on clinical factors such as persistent jaundice or increasing hyperbilirubinemia $>6$ weeks post-transplant. In cases of complexes strictures, preprocedural magnetic resonance cholangiopancreatography was performed at the discretion of the physician performing the ERCP. ERCP was performed with a therapeutic side-viewing endoscope. If localized strictures were present, a high-pressure biliary dilation balloon was used. Balloon sizes ranged from $4 \mathrm{~mm}$ to $10 \mathrm{~mm}$ depending on the diameter of the intrahepatic ducts. After dilation, plastic biliary stents (Cotton-Leung, Cook Medical, USA) were placed across the strictures. In the MultiOrgan Transplant Program, London Health Sciences Centre (London, Ontario), a dedicated transplant surgeon trained in ERCP performs all ERCPs on LT recipients. Biliary strictures were classified as disseminated or localized, involving the hepatic duct bifurcation, donor common hepatic duct or anastomotic site Figure 1.

Statistical analyses were performed using STATA version 10.0 (STATA Corp, USA). Univariate logistic regression was performed. The donor covariates analyzed included: age, sex, cause of death, body mass index, WIT, cold ischemia time (CIT) and time of MAP $<55 \mathrm{mmHg}$.
TABLE 1

Characteristics of DCD and DBD groups

\begin{tabular}{lcc}
\hline & DCD $(\mathbf{n}=\mathbf{3 6})$ & DBD $(\mathbf{n}=\mathbf{3 2 7})$ \\
\hline Donor & & \\
Age, years & $41.8 \pm 13.19$ & $45.93 \pm 10.04$ \\
Cold ischemia time, $\mathrm{h}$ & $5.6 \pm 1.1$ & $7.2 \pm 2.5$ \\
Warm ischemia time, min & $35 \pm 18$ & $\mathrm{NA}$ \\
Height, cm & $170 \pm 9.2$ & $168 \pm 19$ \\
COD (CVA/trauma/anoxia/other) & $19 / 12 / 4 / 1$ & $150 / 101 / 60 / 16$ \\
Donor risk index & $2.03 \pm 0.35$ & $1.51 \pm 0.39$ \\
Recipient & & \\
Age, years & $53.6 \pm 8$ & $54.95 \pm 10.07$ \\
Sex, male/female, $\mathrm{n} / \mathrm{n}$ & $30 / 6$ & $238 / 89$ \\
Race, white/black/other & $34 / 0 / 2$ & $310 / 0 / 17$ \\
MELD score & $17.5 \pm 8.3$ & $18.98 \pm 9.79$ \\
\hline
\end{tabular}

Data presented as mean $\pm S D$ unless otherwise indicated. COD Cause of death; CVA Cerebral vascular accident; DBD Donation after brain death; DCD Donation after cardiac death; MELD Model for End-stage Liver Disease; NA Not applicable

Recipient Model for End-Stage Liver Disease (MELD)score was also examined. Due to the small sample size, multivariate-adjusted logistic regression was not performed due to concerns about the dimensionality of the data. All statistical tests were considered to be significant at $\mathrm{P}<0.05$.

\section{RESULTS}

A total of 36 patients underwent DCD LT between August 2006 and September 2011 . The mean $( \pm \mathrm{SD})$ donor age was $41.8 \pm 13.19$ years. The median WIT was $27 \mathrm{~min}$ (range $18 \mathrm{~min}$ to $124 \mathrm{~min}$ ) and the mean CIT was $5.6 \pm 1.1 \mathrm{~h}$. The mean recipient age was $53.6 \pm 8.0$ years and the mean MELD score was $17.5 \pm 8.3$. Donor and recipient characteristics are summarized in Table 1. One- and two-year patient survival rates were $91 \%$ and $80 \%$, respectively. One- and two-year graft survival rates were $91 \%$ and $73 \%$, respectively.

A total of 327 patients underwent DBD LT between August 2006 and September 2011. The mean donor age was $45.93 \pm 10.04$ years. Mean CIT was $7.2 \pm 2.5 \mathrm{~h}$. The mean recipient age was $54.95 \pm 10.07$ years. The mean MELD score was 18.98 \pm 9.79 . Donor and recipient characteristics are presented in Table 1.

Twelve DCD recipients (33.3\%) required one or more ERCPs due to suspected bile duct complications. In three recipients, no biliary abnormality was identified and serum bilirubin elevation was attributed to other causes (ischemia reperfusion injury, prolonged total parenteral nutrition, severe cholestasis preliver transplant, etc) because it later normalized. In nine recipients (25\%), a biliary complication was detected. All of the patients who developed biliary complications became symptomatic within three months of LT. There were no deaths associated with biliary complications. ITBS included disseminated biliary strictures in two patients (5.6\%), and localized biliary strictures in six patients (three hepatic duct bifurcation strictures and three donor common hepatic duct [CHD] strictures). One recipient developed an anastomotic stricture. None of the DCD recipients developed bile leaks. A summary of the biliary complications is presented in Table 2. One patient with disseminated biliary strictures was retransplanted four months after the original LT, after three attempts at endoscopic management. The other patient with disseminated biliary strictures was initially managed with three endoscopic procedures and ursodeoxycholic acid and has since been retransplanted.

All of the recipients with localized hepatic duct bifurcation strictures and donor CHD strictures were successfully managed with ERCP biliary stenting using plastic stents, with an average of 2.63 procedures per patient during the first year post-transplantation. One patient with a localized hepatic duct bifurcation stricture died from hepatitis $C$ virus recurrence. Three of the remaining five patients with localized strictures are stent free and all have normal graft function (good synthetic 


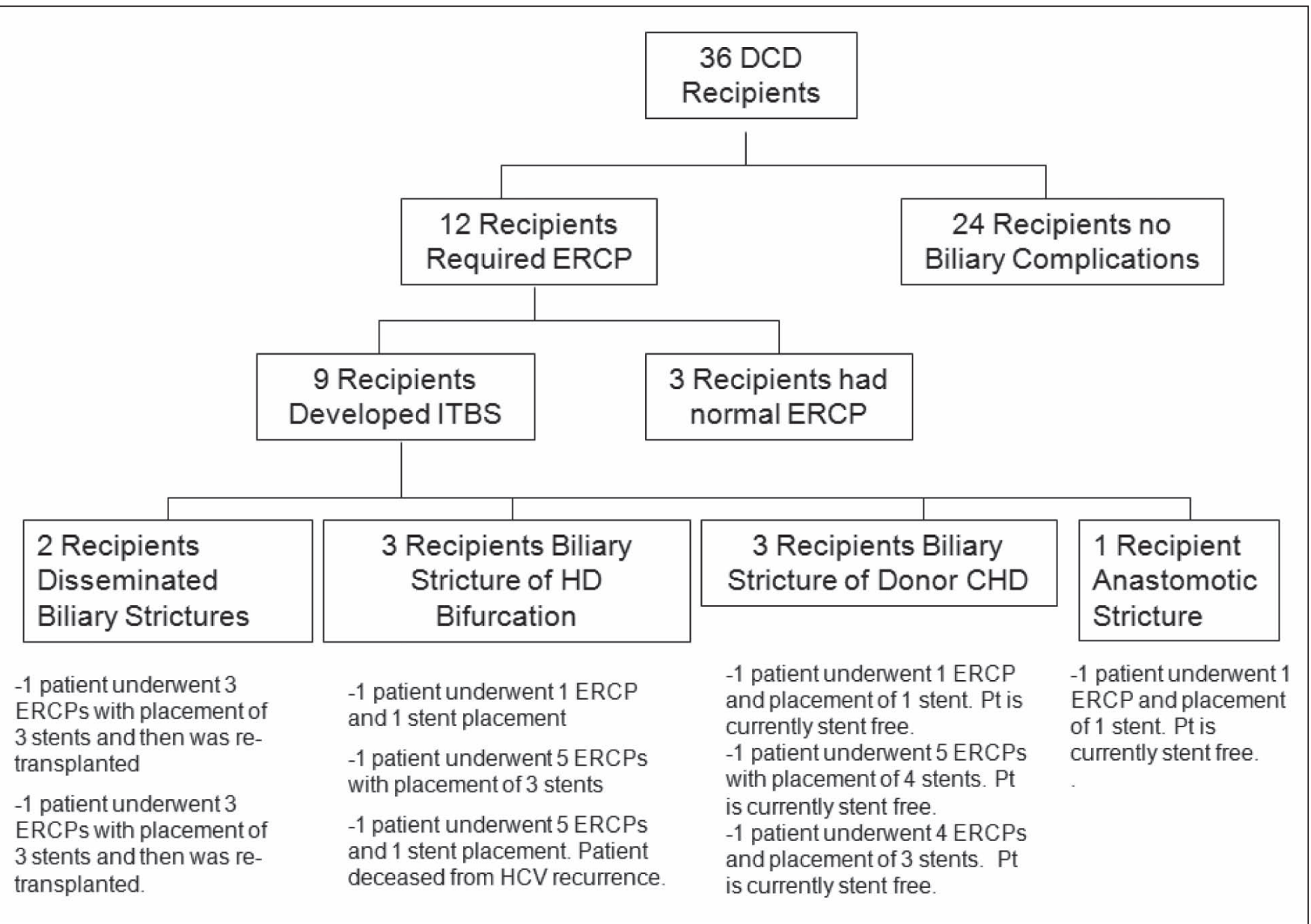

Figure 2) Flow chart of patients undergoing endoscopic retrograde cholangiopancreatography (ERCP) and endoscopic treatment. CHD Common hepatic duct; DCD Donation after cardiac death; HD Hepatic duct; ITBS Ischemic type biliary strictures; Pt Patient

liver function [international normalized ratio <1.3]) and normal transaminase levels (aspartate amino transferase/alanine aminotransferase $<32 \mathrm{IU} / \mathrm{L}$ ) at $>1$ year after LT. Two patients were treated with sequential stents in both the right and left hepatic ducts. In all of the patients, bilirubin levels normalized and jaundice disappeared. None of the patients receiving ERCP developed ERCP-related complications such as pancreatitis or perforation. A flow chart of the biliary complications as well as their management (number of ERCPs and stents) is presented in Figure 2.

DCD LT recipients were compared with DBD LTs performed during the same time period (Table 2). DCD LT recipients experienced a significantly higher rate of diffuse ischemic cholangiopathy than DBD recipients $(5.6 \%$ and $0 \%$, respectively $[\mathrm{P}<0.001])$. DCD LT recipients also experienced a significantly higher rate of hilar strictures than DBD recipients $(8.3 \%$ and $0.3 \%$, respectively $[\mathrm{P}<0.001])$. The two groups did not show any significant difference in the rate of extrahepatic and anastomotic strictures, or in the rate of bile leak.

Univariate logistic regression was performed in DCD graft recipients to determine the odds of biliary complications (of any type). None of the parameters tested were statistically significant. Recipient MELD score showed a nonsignificant trend for predicting the odds of biliary complications $(\mathrm{P}=0.1)$, as did an interaction term of donor age and the time period that the donor had a MAP $<55 \mathrm{mmHg}(\mathrm{P}=0.12)$.

\section{DISCUSSION}

The sensitivity of the biliary tree to ischemic injury makes it particularly vulnerable when livers are procured from DCD donors (7). Events during the period of withdrawal of life support, such as hypoxia, hypoperfusion and microthrombi, can produce irreversible injury that
TABLE 2

Nature of biliary complications in DCD and DBD groups

\begin{tabular}{lccc}
\hline & DCD $(\mathbf{n}=\mathbf{3 6})$ & DBD $(\mathbf{n}=327)$ & $\mathbf{P}$ \\
\hline $\begin{array}{l}\text { Disseminated } \\
\text { Ischemic cholangiopathy }\end{array}$ & $2(5.6)$ & $0(0)$ & $<0.001$ \\
$\begin{array}{l}\text { Localized } \\
\text { Hilar }\end{array}$ & $3(8.3)$ & $1(0.3)$ & $<0.001$ \\
$\quad$ Extrahepatic (donor) & $3(8.3)$ & $13(4)$ & 0.2267 \\
$\quad$ Anastomotic & $1(2.7)$ & $13(4)$ & 0.7232 \\
Bile leak & $0(0)$ & $17(5)$ & 0.1611 \\
\hline
\end{tabular}

Data presented as $n$ (\%) unless otherwise indicated. DBD Donation after brain death; $D C D$ Donation after cardiac death

may not become apparent until weeks after the graft has been transplanted. The higher incidence of biliary complications after DCD LT (32\% to $60 \%$ ) compared with DBD LT (5.8\% to $15 \%$ ) is well documented $(1,3-5,14,15)$. ERCP management of biliary complications post-DBD LT is becoming increasingly ubiquitous (16-18). The use of ERCP for biliary complications after LT has been well established; however, its role in the management of biliary complications in DCD recipients is less well described. Previous authors have reported an ERCP rate of $48 \%$ in DCD recipients (1). In the current study, $30.6 \%$ of the DCD recipients required ERCP. All of the patients who developed biliary complications became symptomatic within three months of transplantation.

In the current study, localized strictures in the hepatic duct bifurcation and the donor CHD were managed with ERCP stenting. Several of these cases required multiple ERCPs with the deployment of 
multiple stents. One patient with a localized hepatic duct bifurcation stricture died from hepatitis $\mathrm{C}$ virus recurrence. None of the remaining five patients who experienced localized strictures have developed graft failure. Previous authors have achieved success in treating biliary strictures with the use of multiple stents in DBD LT recipients (17). While all of the patients in the present study were treated with plastic stents, several authors have begun using self-expanding metallic stents for the treatment of biliary strictures post-DBD LT with reasonable success $(19,20)$. Self-expanding stents have been shown to be superior to plastic stents in the context of biliary malignant obstruction. However, historical reports suggested that their use in bile duct strictures post-liver transplant yield poor results (21). In light of the recent literature showing favourable results, their use in post-transplant strictures could perhaps be revisited in future studies.

There is an increased incidence of diffuse biliary strictures among DCD allografts $(2,3,14,22)$. Our study clearly shows a significantly higher rate of diffuse ischemic cholangiopathy in recipients of DCD allografts compared with DBD allografts. While disseminated biliary strictures are generally believed to be less amenable to ERCP, we were able to manage one patient in the current study with disseminated biliary strictures with multiple ERCP procedures and ursodeoxycholic acid with favourable results until they could be retransplanted. A significant amount of the data describing morbidity and mortality to biliary complications predate the era of routine ERCP. Presently, the rate of biliary complications in patients undergoing DCD LTs is higher than those undergoing DBD LT. Our experience suggests that the majority of biliary complications in patients receiving DCD LTs,

\section{REFERENCES}

1. Barritt AS, Miller CB, Hayashi PH, Dellon ES. Effect of ERCP utilization and biliary complications on post-liver-transplantation mortality and graft survival. Dig Dis Sci 2010;55:3602-9.

2. Abt P, Crawford M, Desai N, Markmann J, Olthoff K, Shaked A. Liver transplantation from controlled nonheart-beating donors: An increased incidence of biliary complications. Transplantation 2003;75:1659-63.

3. Foley DP, Fernandez LA, Leverson G, et al. Donation after cardiac death: The University of Wisconsin experience with liver transplantation. Ann Surg 2005;242:724-31.

4. Skaro AI, Jay CL, Baker TB, et al. The impact of ischemic cholangiopathy in liver transplantation using donors after cardiac death: The untold story. Surgery 2009;146:543-52.

5. Maheshwari A, Maley W, Li Z, Thuluvath PJ. Biliary complications and outcomes of liver transplantation from donors after cardiac death. Liver Transpl 2007;13:1645-53.

6. Graziadei IW, Schwaighofer H, Koch R, et al. Long-term outcome of endoscopic treatment of biliary strictures after liver transplantation. Liver Transpl 2006;12:718-25.

7. Sanchez-UrdazpalL, GoresGJ, Ward EM, et al. Ischemic-type biliary complications after orthotopic liver transplantation. Hepatology 1992;16:49-53.

8. Sanchez-Urdazpal L, Gores GJ, Ward EM, et al. Diagnostic features and clinical outcome of ischemic-type biliary complications after liver transplantation. Hepatology 1993;17:605-9.

9. Nishida S, Nakamura N, Kadono J, et al. Intrahepatic biliary strictures after liver transplantation. J Hepatobiliary Pancreat Surg 2006;13:511-6.

10. Greif F, Bronsther OL, Van Thiel DH, et al. The incidence, timing, and management of biliary tract complications after orthotopic liver transplantation. Ann Surg 1994;219:40-5.

11. Warren KW, Mountain JC, Midell AI. Management of strictures of the biliary tract. Surg Clin North Am 1971;51:711-31.

12. Pasha SF, Harrison ME, Das A, et al. Endoscopic treatment of anastomotic biliary strictures after deceased donor liver transplantation: Outcomes after maximal stent therapy. Gastrointest Endosc 2007;66:44-51. such as recipients of DBD grafts who develop biliary complications, can be effectively treated by endoscopic intervention. Patients who develop disseminated ischemic cholangiopathy ultimately required retransplantation.

In DCD LT recipients, none of the parameters tested were statistically significant predictors of the odds of biliary complications (of any type). Recipient MELD scores had a nonsignificant trend for predicting the odds of biliary complications $(\mathrm{P}=0.1)$, as did an interaction term of donor age and the time period that the donor had a MAP $<55 \mathrm{mmHg}$ $(\mathrm{P}=0.12)$. Previous authors have suggested that a recipient MELD score $\geq 35$, donor age $\geq 50$ years and donor WIT $\geq 35 \mathrm{~min}$ are predictive of graft failure in DCD LT recipients (23). A study examining a larger cohort of DCD transplants would certainly be of value to determine whether the trends for predicting biliary complications achieve statistical significance.

\section{CONCLUSIONS}

There is a trend toward increased incidence of biliary complications in recipients receiving DCD donor livers; however, when diagnosed early, endoscopic stenting can improve outcomes, especially in those with localized strictures in the hepatic duct bifurcation and the donor CHD hilar. Patients with disseminated ischemic cholangiopathy will ultimately require retransplantation.

DISCLOSURE: The authors have no financial disclosures or conflicts of interst to declare. The manuscript did not receive any funding.

13. Hernandez-Alejandro R, Croome K, Quan D, et al. Increased risk of severe recurrence of hepatitis $C$ virus in liver transplant recipients of DCD (donation after cardiac death) allografts. Transplantation 2011;92:686-9.

14. Selck FW, Grossman EB, Ranter LE, et al. Utilization, outcomes, and retransplantation of liver allografts from donationafter cardiac death: Implications for further expansion of the deceased-donor pool. Ann Surg 2008;248:599-607.

15. Abt P, Fischer C, Singhal A. Donation after cardiac death in the US: History and use. J Am Coll Surg 2006;203:208-25.

16. Sanna C, Saracco GM, Reggio D, et al. Endoscopic retrograde cholangiopancreatography in patients with biliary complications after orthotopic liver transplantation: Outcomes and complications. Transplant Proc 2009;41:1319-21.

17. Tabibian JH, Asham EH, Goldstein L, et al. Endoscopic treatment with multiple stents for post-liver-transplantation nonanastomotic biliary strictures. Gastrointest Endosc 2009;69:1236-43.

18. Rizk RS, McVicar JP, Emond MJ, et al. Endoscopic management of biliary strictures in liver transplant recipients: Effect on patient and graft survival. Gastrointest Endosc 1998;47:128-35.

19. Vandenbroucke F, Plasse M, Dagenais M, Lapointe R, Lêtourneau R, Roy A. Treatment of post liver transplantation bile duct stricture with self-expandable metallic stent. HPB (Oxford) 2006;8:202-5.

20. Tee H, James MW, Kaffes AJ. Placement of removable metal biliary stent in post-orthotopic liver transplantation anastomotic stricture. World J Gastroenterol 2010;16:3597-600.

21. Culp WC, McCowan TC, Lieberman RP, Goertzen TC, LeVeen RF, Heffron TG. Biliary strictures in liver transplant recipients: Treatment with metal stents. Radiology 1996;199:339-46.

22. Chan EY, Olson LC, Kisthard JA, et al. Ischemic cholangiopathy following liver transplantation from donation after cardiac death donors. Liver Transpl 2008;14:604-10.

23. MathurAK, Heimbach J, Steffick DE, Sonnenday CJ, Goodrich NP, Merion RM. Donation after cardiac death liver transplantation: Predictors of outcome. Am J Transpl 2010;11:2512-9. 


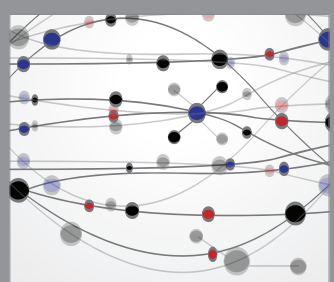

The Scientific World Journal
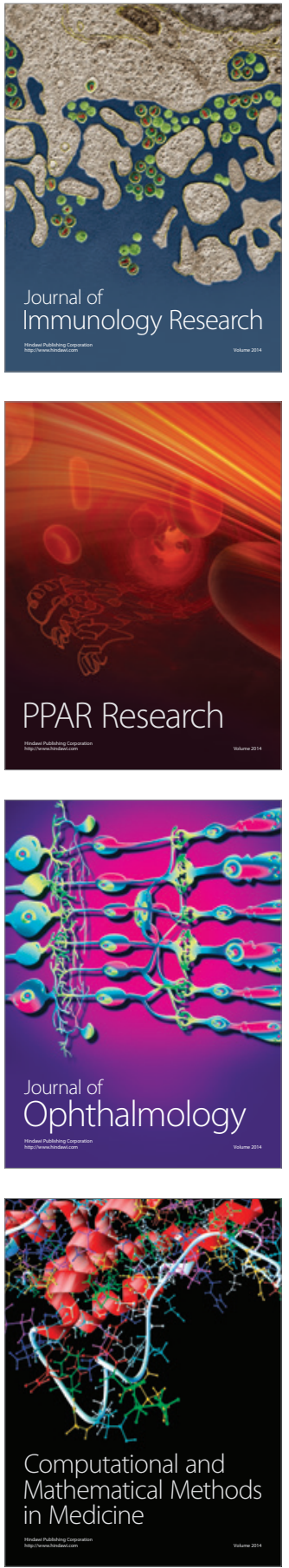

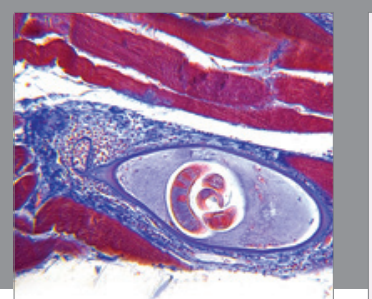

Gastroenterology Research and Practice

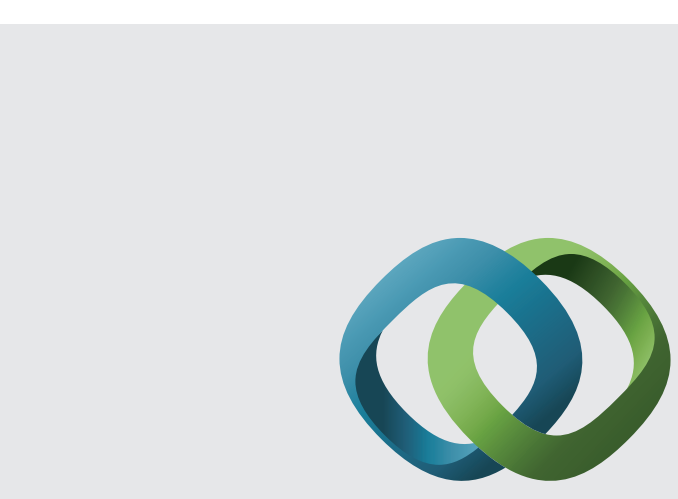

\section{Hindawi}

Submit your manuscripts at

http://www.hindawi.com
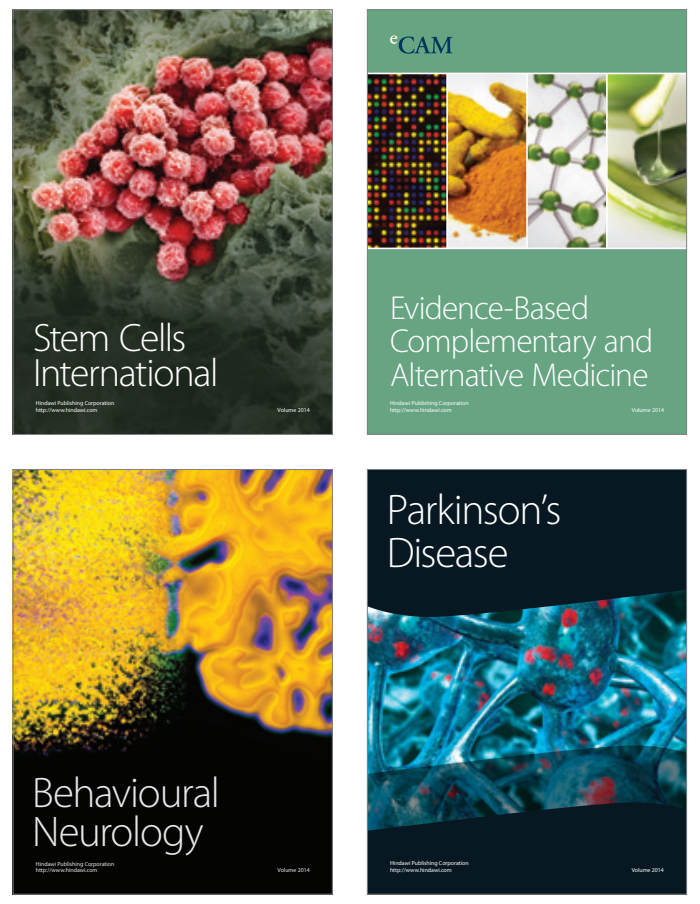
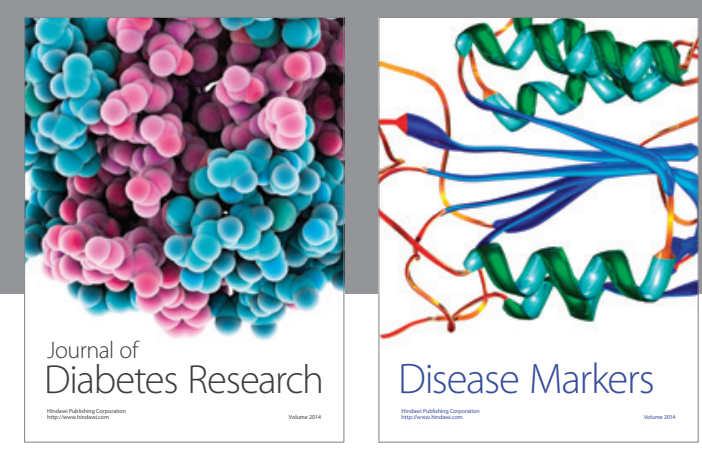

Disease Markers
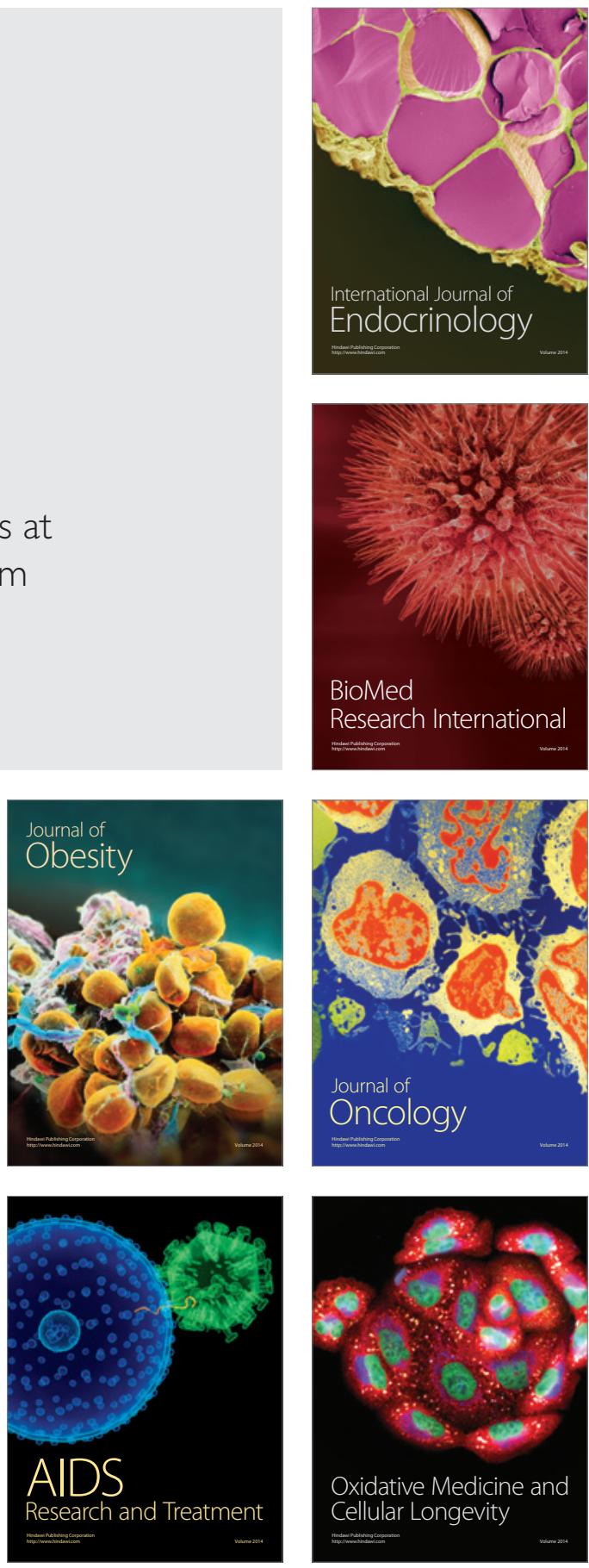